\title{
A DIACHRONIC STUDY OF THE NP STRUCTURE IN GHANAIAN NEWSPAPER EDITORIALS
}

\author{
Mr. Isaac Afful \\ Department of English, University of Cape Coast, Ghana \\ lafful8@gmail.com
}

\begin{abstract}
In the last few decades, researchers have grown much interest in analyzing the structure of the NP in various domains. Dwelling on Quirk et al's (1985) framework on NP complexities, this study investigates the NP structure in editorials form the Daily Graphic. Being a diachronic study, nine editorials form 1988, 1998 and 2008 were analysed. The analysis and discussion point to two key findings. First, there has been a gradual increase in the use of Head + PP structures in Ghanaian newspaper editorials. Second, the Determiner+Head has been the most preferred structure of premodification in editorials. These findings have implications for print media discourse, Historical Linguistics, text construction and for further research.
\end{abstract}

Key expressions: diachronic studies; editorials; print media; Applied Linguistics and noun phrase

\section{Council for Innovative Research}

Peer Review Research Publishing System

Journal: Journal of Advances in Linguistics

Vol. 5, No. 1

editorjalonline@gmail.com

www.cirjal.com 
The English Language is used as the official language in Ghana. It is the language encountered in public domains of the country. It is used in administration of the country and is used as the chief mode of communication in law, politics, sports, international relations and in the media. Generally, the media refers to institutions that deal with the packaging and dissemination of information to the public. Broadly, there are two categories of the media - the electronic media and the print media. The print media are defined as comprising newspapers and magazines that are printed for mass readership. The electronic media comprise radio and television. They involve the transmission by the air waves, cable or satellite of sound or images for simultaneous reception by a mass audience.

Newspapers play an important role in disseminating information to the Ghanaian populace. A newspaper can be defined as a publication, usually in a sheet form, intended for general circulation, and published regularly at short intervals, containing intelligence of current events and news of general interest (Picard \& Brody, 1997). Currently, 136 newspapers are published in Ghana (Wikipedia, 2011). Some of these newspapers are state-owned while a majority of them are private-owned. The state-owned newspapers include the Daily Graphic, the Ghanaian Times and the Evening News. Notable among the private-owned newspapers are the Daily Guide, the New Crusading Guide, The Weekly Spectator and The Palaver. A newspaper comprises various genres or sub-genres. These include editorials, banner headlines, classifieds, and feature articles, letters to the editor and front page stories.

A newspaper editorial, according to Danesi (2009), is an article in a newspaper that gives the opinion of the editor or publisher on a topic or item of news. It is an article or column in a newspaper or magazine written by the editor or under his or her direction, giving opinions about a subject or event. Editorials are thus, comments on news items of national concern which attract the attention of the editor. Such news items may be political, economic, educational, religious or general socio-cultural issues that border on the welfare of the people. These written comments are published in the national dailies or magazines and are collectively known as "editorials" That is, it is an article or essay expressing the newspaper's point of view on a specific subject. It can be written by the editor-in-chief or a senior staff journalist.

Over the years, researchers have grown much interested in investigating the noun phrase in various languages. The most dominant ones are studies on Romance, Balkan, Asian and Germanic languages (Dimitrova- Vulchanova, 1998; Guisti, 2002; Cheung, 2007). Earlier studies such as that of Hudson-Ettle (1990) have focused on diachronic studies involving the noun phrase.

This study seeks to do a diachronic study of the structure of noun phrases in one of the most-read newspapers in Ghana the Daily Graphic. The following questions have been formulated to guide the present research:

1. What kinds of NPs are evident in editorials from the Daily Graphic?

2. What premodifiers are dominantly used in the NPs of editorials of the Daily Graphic?

3. What postmodifiers are dominantly used in the NPs of editorials of the Daily Graphic?

\subsection{REVIEW OF RELATED LITERATURE}

\subsection{Noun Phrases and Its Structure}

According to Biber (1988), a noun phrase (henceforth NP) in the strict sense consists of a noun as head, either alone or accompanied by determiners(which specify the reference of the noun; and modifiers(which describe or classify the entity denoted by the head noun). As Greenbaum (1996) notes, the head of the NP is a noun, a pronoun, a nominal adjective, or a numeral. It may be introduced by one or more determiners, and it may be modified by one or more premodifiers and by one or more postmodifiers. For Biber (1998),

"Premodifiers differ from postmodifiers in two major ways: first, premodifiers are consistently more condensed than postmodifiers, using many fewer words (often a single word) to convey similar information. Second, premodifiers are much less explicit in identifying the meaning relationship that exists between the modifier and head noun. (1999:588).

NPs can be simple or complex. Simple NPs have grammatical elements that premodify the noun head while complex NPs showpost modification. Premodifiers are those grammatical elements that precede the head word which is nominal. The most common premodifiers of nouns are determiners, adjectives, nouns, genitive noun phrases, participles, and numerals and the most common postmodifiers of nouns are prepositional phrases and relative clauses (finite or non-finite).

The determiners at the premodification section of noun phrases can be categorized into three. These are predetermines, central determiners and post determiners. The predeterminers can further be sub-classified into three. First, there are words that show quantity. Examples are, all, both, half and such. The second group includes words that show the occurrence of events such as twice, once, thrice etc. The final group comprise fractions such as two-thirds, three-fourths, one tenth etc. The central determiners are the core determiners that premodify the head of noun phrases. They include articles (such as: a, an, the), demonstratives (such as this, these), possessive determiners (such as my, your, her, our) and interrogative determiners (such as which, whose and what). The post determiners come after the central determiners. They include, cardinal numbers (such as one, tow, three...), ordinals (such as first, second, third ...), quantifiers (such as some, few, a few, a lot, several, little, many...) and general ordinals (such as former, next, latter, last etc.) 
Adjectives can also premodify the NP. By form, adjectives that premodifyNPs include binominals or compound nouns, general adjectives and participles functioning as adjectives. Examples of compound nouns that have adjectival function are as follow:
1. The University lecture [university premodifies the noun head, lecturer]
2. The bar man
[bar premodifies the head, man]
3. The Students' hostel
[students'premodify the head, hostel]

The adjectives that premodify nouns are sequentially arranged. The following order of adjectives, according to Greenbaum (1996), can thus be identified: general adjectives (such as beautiful, nice, big, large...), adjectives related to color (such as white, greenish, velvet...), adjectives related to age (such as old, young, sexagenarian etc.), adjectives related to provenance or origin (such as Ghanaian, Gothic, American ...), denominals (such as criminal, social, moraletc), participial adjectives (such as well-groomed, dyingetc). The example below illustrates the order of adjectives that premodify NPS:

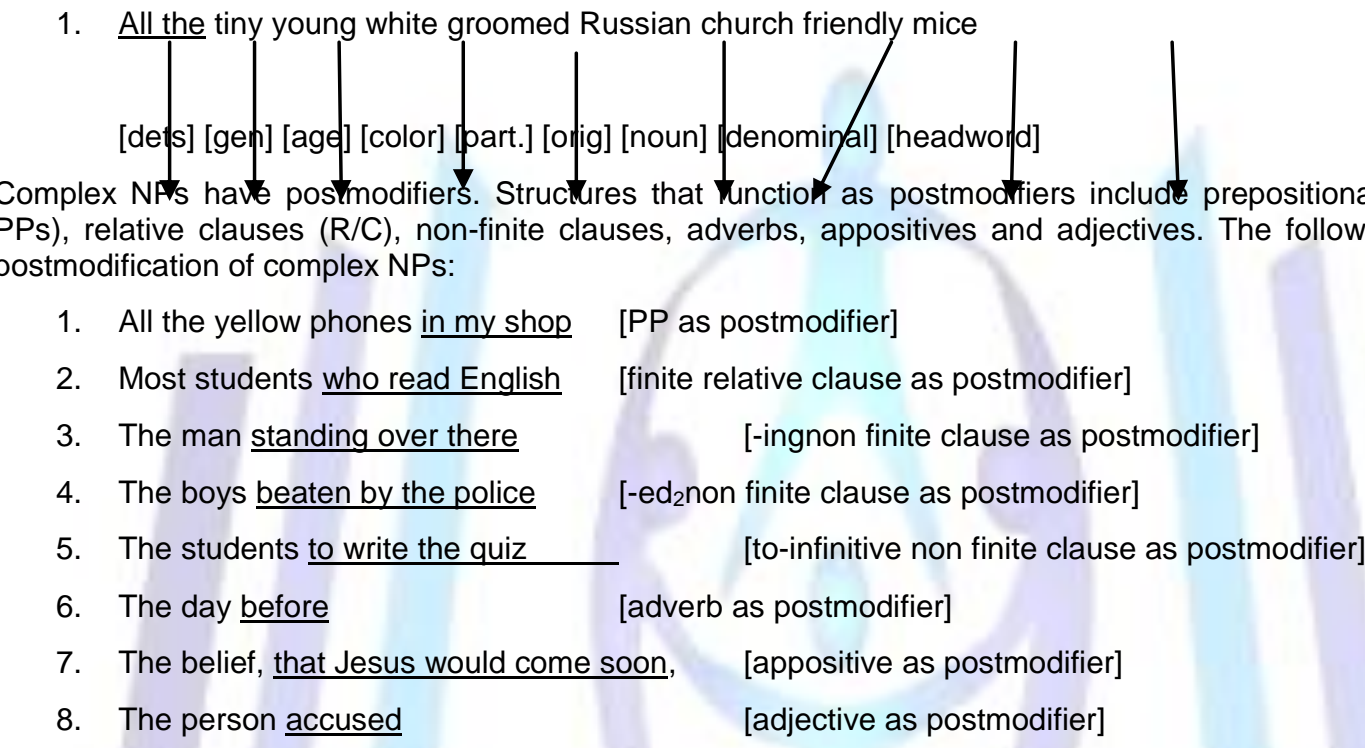

\subsection{Review of Empirical Studies on NPs}

As earlier indicated, noun phrases have been studied across various perspectives. While some studies (such as Dimitrova- Vulchanova, 1998; Guisti, 2002; Cheung 2007) have focused on the syntax of NPs in Romanic and Balkan languages, others have focused on NPs in professional genres (Hudson-Ettle, 1990; Maester, 1998, Weistin\&Geisler, 2011).

Dimitrova-Vulchanova\&Giusti(1998) discuss the properties of syntax of NPs in three Balkan languages: Albania, Bulgarian and Rumanian. The study specifically looked at the ordering of premodifiers and articles in NPs across the three languages. The study argues that these three languages display a functional projection to host syntactic movements such as topic and focus movements within their NPs. The analysis and discussion pointed out that in Albanian languages, an ordinal adjective precedes a descriptive adjective. About Bulgarian language, the study shows that ordinal adjectives such as first and last are always be prenominal in both definite and indefinite NPs. Concerning the issue of NP movement, the study concluded that the enclitic article does not trigger a noun head movement.

In a similar study, Giusit (2002) investigates the functional structure of NPs in Romance, German and Balkan languages. Specifically, the paper deals with premodifying articles and demonstratives that function as referential operators within the NPs in the three languages. Using Chomsky's bare phrase structure approach (1993), the study argues that demonstratives such as possessive adjectives, referential adjectives, possessive NPs and compound proper names vary in terms of positioning and function, from articles across the three languages. However, it was also revealed that these demonstratives have semantic implications in that, they contribute semantic content to the NP at their maximal projections. These studies, though ill-balanced and ancient, are related to the present study since both investigates the NP structure.

In a more recent study, Cheung (2007) investigates the NP structure of Jingpo. He focuses on the use of demonstratives and plural morpheme (-ni) used in their NP structures. His findings indicate that Jingpo marks plural morpheme (such as ni) on common count nouns. Second, it was revealed that demonstratives have a free range of occurrence as they can occur before or after the noun head either as Demonstrative + Noun + Clasifier or as Noun + Demonstrative + Classifier +Noun. The study, though significant and informative, did not deal with current studies.

The literature also indicates that studies on NP structures have focused in professional genres. For instance, Hudson-Ettle (1990) does a comparative study on the debating issue of orality and formality and how they are related to the structure of NPs in the registers of British and Kenyan English. Her corpus comprised four different text types: social letters, short 
stories, feature articles from the British Uppsala Press Corpus and Uppsala Corpus of Travel Texts and institutional editorials from a corpus of English from Kenya. Using Biber (1998)'s model, the study analysed the four text types with respect to the frequency of adjectival premodification in NPs. The NP analysis revealed that social letters and short stories show fewer NP complexities than the other two genres.

Some researchers have also focused on diachronic studies of NPs in various media genres.

Mardh's (1980) article explores NP complexities in the headlines of two British newspapers the Daily Mirror and by The Times. Having analysed 2222 NPs of verbal headlines in the Times and 530 in the Daily Mirror newspapers anddwelling on Quirk et al's (1985) framework, the study reveals quite surprisingly that the headlines captured in verbal headlines were more complex than those captioned in nominal headlines.

Still on newspaper headlines, Maestre (1998)'s seminal work on complexity of NPs in news headlines is worth reviewing here. Her diachronic study explores headlines of front page, home news, the arts, business news, sports news and letters to the editor published in the Times newspaper from 1970 to 1990.The main aim was to explore the variation of the structure of simple and complex NPs in the corpus and to establish possible differences between the NPs. The headlines were both nominal and verbal in structure. Having used Quirk et al's (1985) framework of NP complexity, the study revealed twenty seven types of independent NP complexity. Out of these, five core types were evident. These are: Head + Postmodifier (H P2); Premodifier + Head (P1 H); Premodifier + Head + Postmodifier (Pm1 H Pm2); Determiner + Head + Postmodifier (D H Pm2) and Determiner + Premodifier + Head+ Postmodifier (D Pm1 H Pm2). Again, significant differences were detected between the NPs in verbal and nominal headlines. The study also revealed that the percentage for complex NPs in both verbal and nominal headlines were higher than those identified by Quirk et al (1985). Like these two studies, this paper dwells on Quirk et al (1985) classification of complexities in NPs.

In a more recent study on diachronic studies of NPs in print media discourse, Westin\&Geisler (2011) investigated the diachronic change in 20th-century newspaper editorials published between 1900 and 1993 in the three newspapers the Guardian, the Daily Telegraph and The Times. Unlike Maestre's study (1998), the analysis here was based on the multidimensional framework as presented in Biber $(1988,1995)$. Specifically, the study analysed 554 editorials with regard to five dimensions: involved versus informational production, narrative versus non-narrative concerns, the degree of referential elaboration, persuasive/ argumentative focus, and abstract versus non-abstract style. The results of the dimension score analyses show that, during the 20th century,the language of British up-market editorials became less narrative, but more persuasive and argumentative.

The next unit discusses the methodology used for the data collection and analysis.

\subsection{METHODOLOGY}

\subsection{Research Design and Data Source}

The study employed a mixed study approach in analysing the data collected. This involved both quantitative and qualitative methods. The quantitative method enabled the researcher to present figures and facts in tables and other visuals in order to aid understanding while the qualitative method aided the researchers in providing illustrative sample texts and explaining the factors that influenced the various facts obtained.

The data collected for this study were from editorials published in the Daily Graphic (formerly called the People's Graphic in the 1980s). Being a diachronic study, the study investigated the structure of the NPs used in editorials in three periods: 1988,1998 and 2008.

\subsection{Sampling Technique, Sample Size and Data Collection Procedure}

The research analysed nine editorials. Three editorials for each year were selected. The first publications for each year were conveniently sampled. For each first quarter of the year, an editorial was randomly selected for analysis. Thus, from January to April, May to August and September to December, an editorial was selected from these periods for the analysis. The convenience sampling method was mainly used in collecting data for the study. A convenience sample is motivated by analytical interest in an available body of texts that is known not to include all texts in a population that the analyst is concerned with. Such a sample is convenient in the sense that the analyst does not care to make an effort or find it too difficult to sample from that population (Krippendorf, 2004).

Two main reasons informed the choice of the Daily Graphic. The first reason stems from the fact that it has gained some prestige among Ghanaians and has quite a large audience. In Ghana, the Daily Graphic for instance, is synonymous to newspaper to the average Ghanaian. Thus, any form of newspaper research in Ghana may want to begin with them. Secondly, the competence and quality of news delivery by the reporters and editors of the Daily Graphic newspaper informed the choice. The textual data were available at the Main Library of the University of Cape Coast, an institution where the present researcher is currently pursuing a two-year post graduate degree programme in English.

\subsection{ANALYSIS AND DISCUSSION}

With the aid of some visuals such as tables and charts, this section presents the analysis on premodifiers first and that of the premodifiers follows. 


\subsection{Premodfication of the NP in the Editorials of the Daily Graphic}

The analysis of the NPs in the editorials of the Daily Graphic showed that nine types of premodifiers are evident at the premodification of NPs. The nine forms identified are Determiner + Head (DH); Determiner +Adjective + Head (DAH); Determiner + two adjectives + Head (DAAH); Determiner + Adjective + Noun + Head (DANH); Determiner + Adjective + two nouns + Head (DANNH); Determiner + Noun + Head (DNH); Noun + Head (NH), Determiner +two nouns + Head $(\mathrm{DNNH})$; Determiner + (Adjectives) + Genitive + Head (DGH). The bar chart below (Figure 2) shows the frequency of occurrence of these forms as evident in the data:

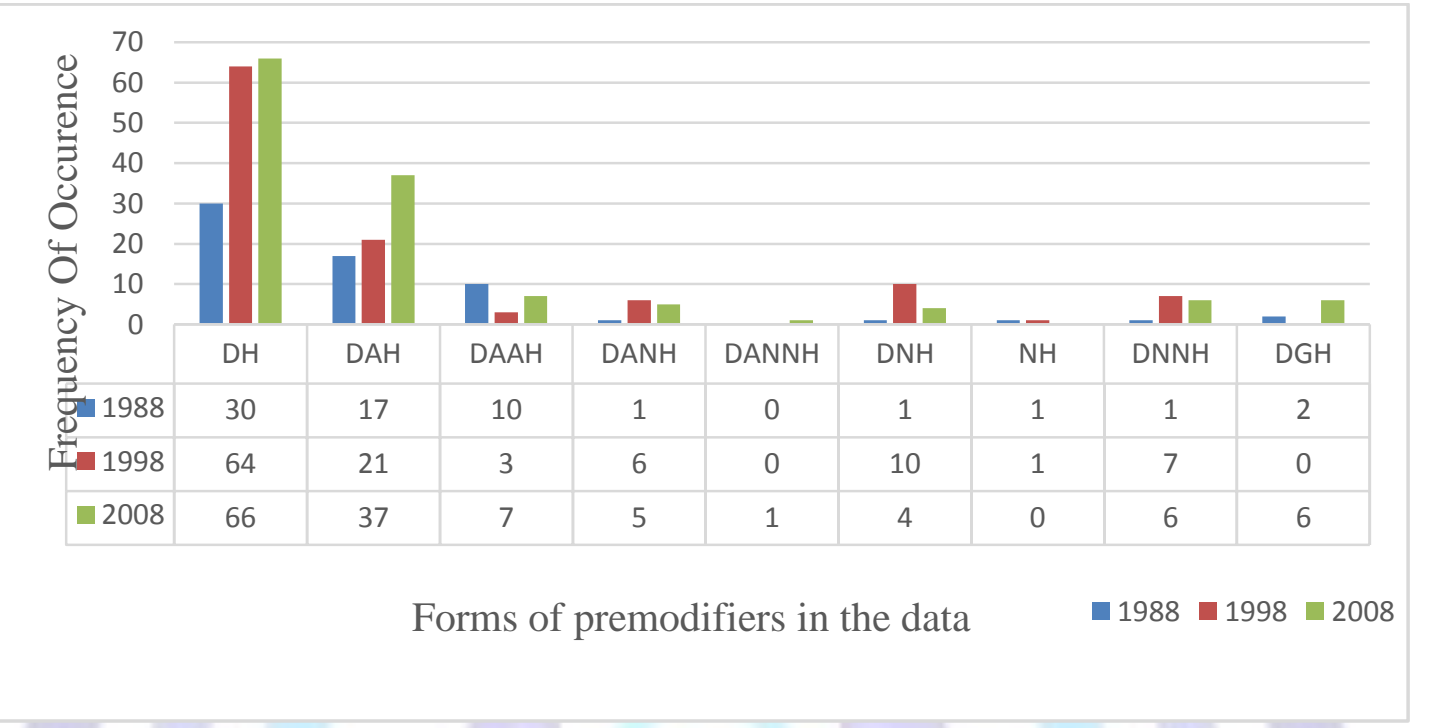

Figure 1: A Bar Chart presenting the frequency distribution of occurrence of premodifiers

The table below presents a simplified version of the frequency of distribution of the forms of premodifiers identified in the data:

Table 1: Table representing the frequency distribution of premodifiers in the data

\begin{tabular}{lcc}
\hline Type of Premodifier & Frequency & Percentage (\%) \\
\hline DH & 160 & $52.1 \%$ \\
DAH & 75 & $24.4 \%$ \\
DAAH & 20 & $6.5 \%$ \\
DANH & 12 & $3.9 \%$ \\
DANNH & 1 & $0.3 \%$ \\
DNH & 15 & $4.9 \%$ \\
NH & 2 & $9.9 \%$ \\
DNNH & 14 & $2.6 \%$ \\
\hline Total & 307 & $0.6 \%$ \\
\hline
\end{tabular}


The four dominant premodifiers types from the data are presented below:

\section{a. Determiner + Head $(D H)$}

The analysis revealed that NPs in editorials of Ghanaian newspapers make dominant use of the Determiner+ Head structure. From the data set, this kind of premodification was the most frequent as it occurs 160 times representing $52.1 \%$ occurrence. This is not surprising since every noun phrase is generally preceded by a determiner which is usually an article (Quirk et al, 1985). Figure 1 depicts that there has been a subtle increase in the use of DH premodifiers in editorials. The determiners comprised predeterminers (henceforth PD) and central determiners (henceforth CD). Postdeterminers (henceforth PSD) rarely occurred in the data set. The table below presents the frequency of distribution of determiners found in the data set:

Table 2: Table representing the distribution of determiners in $\mathrm{D} H$ structures

\begin{tabular}{lccc}
\hline YEAR & PD & CD & PSD \\
\hline 1988 & 1 & 29 & - \\
1998 & 1 & 63 & - \\
2008 & 3 & 63 & - \\
\hline Total & $\mathbf{5}$ & $\mathbf{1 5 4}$ & - \\
\hline
\end{tabular}

Examples of the D H structure with PDs (in italics) are:

1. In the Gold Coast, such sentiments... (March 1, 1988)

2. All the associations .... (November 2,1998$)$

3. ...with all hopes and certainties, ... (December 1, 2008)

4. All over the world (December 1, 2008)

5. From all indicators ... (December 1, 2008)

The analysis reveals that the PDs were dominantly used in December 2008 - the month for the elections.

The CDs were mostly the definite articleand demonstrative pronouns. They occurred 154 times out of 160 . The following examples are worth mentioning:

1. The Whiteman is cheating us (March 1, 1988)

2. Initially, there were some misgivings (May 2, 1988)

3. We went through those times (February 2, 1998)

4. $\quad$ Their interest needs to be protected (June 1, 1998)

5. We need a leader who would look for the solution (December 1, 2008)

b. Determiner + Adjective + Head (henceforth DAH)

The data also revealed that DAH structures are frequently used in the premodification of NPs in editorials. From the data set, it recorded the second highest frequency of occurrence, occurring 75 times $(24.4 \%)$. It can also be concluded, per the chart in Figure 1, that there has been a great increase in the usage of DAH structures in editorials. It occurred 17 times, 21 times and 37 times in the editorials of 1988, 1998 and 2008 respectively. As can be seen, DAH premodifiers occurred most in the 2008 editorials. The following examples illustrate their usage:

1. This will heighten the political temperature (March 1, 1988)

2. ...to undertake an effective diagnosis (June 1, 1998)

3. ...will mark a drastic reduction (January 1, 2008)

4. ..to play for the ultimate prize (January 1, 2008)

Morphologically, these adjectives had adjectival ending such as $\{$-ic $\},\{$-al $\}$ and $\{$-ive). It must be noted that nouns that function as adjectives were not included in this category.

\section{c. Determiners + Compound Adjectives + Head (D A A H)}

The analysis of the data also indicates that editorials in the Daily Graphic usually contain NPs with the DAAH structure. They occurred 20 times (representing 6.5 occurrence) as seen from Table 2. Again, Figure 1 shows that there has been a decrease in the occurrence of this structure over the last few decades. The highest occurrence was recorded in the editorials of 1988 while the least was in 1998. It must be noted that some of the general adjectives and participial adjectives used here were coordinated compound adjectives joined by the coordinators, and or or. This assertion is instantiated below: 
1. On our front page is the sad and debilitating story (September 1, 1998)

2. This equitable and judicious approach... (June 1,1998)

3. ... of the dead or dying factory (September 1, 1998)

Other adjectives in DAAH premodifiers were sequentially arranged following the order as cited in Greenbaum (1996):

4. ... a dependent, import-oriented economy (September 1, 1988)

5. The much trumpeted issues (June 1, 1998)

6. This is a crucial transitional period (June 1, 1998)

7. ...would want to savour the famed Ghanaian hospitality (January 1,2008 )

8. 16 top African nations (January 1, 2008)

The words in italics in the few examples above illustrate the order of premodifying adjectives found in the data.

d. Determiner + Binominals $(D N H)$

The final premodifying structure to be discussed is the D N H structure. This occurred 15 times (representing $4.9 \%$ occurrence). This occurred once in 1988, 10 times in 1998 and four times in 2008 editorials of the Daily Graphic. In this structure, a noun premodifier(in addition to the determiner) precedes the noun head. Thus, binominals are formed. The following instances can be identified in the data:

1. The tariff increases have been ... (February 2, 1998)

2. The divestiture program (November 2, 1998)

3. The internet facilities have improved... (August 1, 2008)

The italicised words in the examples above represent the nouns that function as premodifiers of their respective noun heads.

Clearly, the following conclusions can be made from the analysis. Diachronically, it is revealed that some kinds of premodifiers and post modifiers are preferred in writing editorials. With regard to premodifiers, the data revealed that there is the high preference of $\mathrm{DH}$ and DAH structures to the other premodifiers. Second, it is revealed that there is a decrease in the usage of DAAH and DNH structures. As regards postmodifiers, it is revealed that despite few decreases, there is a general increase in the use of PP postmodifiers and relative clause postmodifiers.

\subsection{Postmodificationof NPs in the Editorials of the Daily Graphic}

The analysis show that writers of editorials in the Daily Graphic make use of postmodifiers. This was seen across all three years under study. Broadly speaking, three main types of postmodifiers were identified from the data set. They include prepositional phrases (PPs), relative clauses (R/C) and -ingand - $\mathrm{ed}_{2}$ non-finite clauses (nfc). The chart below illustrates the frequency of occurrence of postmodifiers identified from the sample:

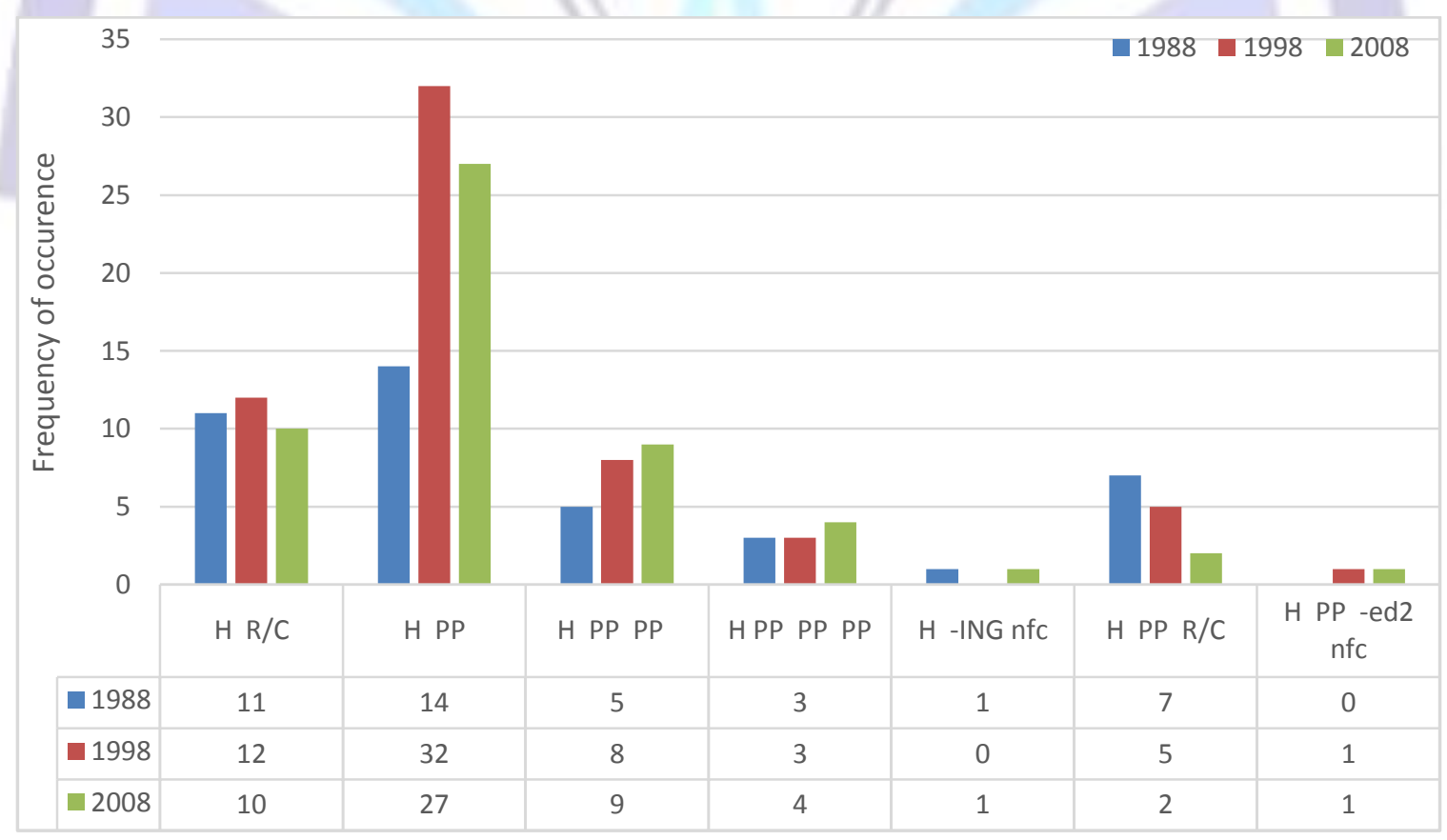


Figure 2: Bar Chart showing the frequency of distribution of postmodification

From Figure 2, it is seen that, over the years, writers of editorials in the Daily Graphic make use of complex noun phrases. As Greenbaum (1996) notes, complex noun phrases usually have heavy postmodification. This is confirmed by Biber (1999) who intimates there is no limit to the complexity of NPs. The most common type of structures that function as postmodifiers of the noun heads used in these editorials are prepositional phrases, relative clauses and -ing clauses. Their frequency distribution is presented in the table below:

Table 3: Table presenting the frequency distribution of postmodifiers in the data

\begin{tabular}{llc}
\hline Type of Postmodifier & Frequency & Percentage (\%) \\
\hline H R/C & 33 & $21.2 \%$ \\
H PP & 73 & $46.8 \%$ \\
H PP PP & 22 & $14.1 \%$ \\
H PP PPPP & 10 & $6.4 \%$ \\
H PP R/C & 14 & $8.9 \%$ \\
H PP -ING NFC & 2 & $1.3 \%$ \\
H PP -ED ${ }_{2}$ NFC & 2 & $1.3 \%$ \\
\hline Total & 156 & $100 \%$ \\
\hline
\end{tabular}

These structures are further discussed below:

\section{Headword+ Prepositional Phrase}

The data set revealed that most of the complex noun phrases had PPs as their post modifiers. This type of postmodification had the greatest frequency of occurrence. The data revealed that it is possible to have one, two or three PPs at the postmodification section of the noun phrase. Thus, the PPs were realised as H PP, H PP PP, H PP PPPP. As Biber (1999) notes, the use of PPs is an effective way of placing high amounts of information into idea units and expanding their sizes.

\subsubsection{Headword + Single PP (H PP)}

The data set revealed that the postmodification of noun phrases in the editorials of the Daily Graphic are usually single PPs. From the data set, this structure occurred 73 times representing 46.8\% occurrence. As Biber (1999:248) observes, the PP is by far the most common type of postmodifiers in English. The following examples illustrate the occurrence of such single PP structures (H PP) that postmodify their various noun heads:

1. The march of the ex-servicemen helped ..... ( H PP) [March 1, 1988]

2. The new tariffs for electricity have shot up. (H PP) [ Feb 2, 1998]

3. We stand the chanceof boosting our tourism (H PP) [Jan. 1, 2008]

\subsubsection{Headword+ Two PPs (H PP PP)}

It was also revealed that two PPs that postmodify the headword. This structure occurred 22 times (14.1\%). Here, two PPs that postmodify a noun phrase are considered as two district constituents rather than a single PP nesting. From Figure 2, it is seen that there has been an increase in the use of this type of postmodifier in Ghanaian editorials. Whereas the structure occurred twice in 1988, it occurred 8 times and 9 times in 1988 and 2008 respectively. The following examples illustrate this point:

4. There was a real problemfor the creationof identity, formation and development. (H PP PP) [May 2, 1988]

5. The effectsof the criseson the informal sector ( H PP PP) [June 1, 1998] 
6. According to the 2007 World Bank Reporton internet usein the world (H PP PP) [Aug 2, 2008]

\subsubsection{Headword + three PPS (H PP PP PP)}

The noun head from the data set also had three PPs postmodifying it. This was seen in all three years. This structure occurred 10 times (6.4\% occurrence). Similar to the H PP PP structure, the H PP PPPP showed an increase in its usage in the editorials of the Daily Graphic. It occurred thrice in the editorials of 1988 and 1998 but increased to four in 2008. The following examples illustrate this assertion:

7. The launchingof the blue bookon the modalitiesfor the District Assembly elections(H PP PP PP) [May 2, 1988]

8. There was the need for the efficiencyin the operationsof the service providers (H PP PP PP) [Feb 2, 1998]

9. ...to put up oneof the most important competitive strugglesfor the leadershipof the country (H PP PP PP) [Jan 1, 2008]

\subsubsection{Headword + PP + R/C}

The PPs also combined with relative clauses $(\mathrm{R} / \mathrm{C})$ in the postmodifying function. This occurred 14 times representing $8.9 \%$ occurrence in the data set. The following examples from the data set can be cited in this regard:

10. On our front page story is the sad and debilitating storyof the either dead or dying garment factorieswhich have been outdone by inferior and cheap clothing. (H PP R/C) [Sept. 1, 1988]

11. That was the questionof lifeline consumptionwhich was pegged at 100 units. (H PP R/C) [Feb 2, 1998]

12. ...to have a better grasp of factorsthat are vital in determining power tariffs. (H PP R/C). [Feb 2, 1998]

13. ... stands to be the greatest beneficiaryof the good thingsthat would come with the hosting of the Ghana 2008 tournament (H PP R/C) [Jan 1, 2008]

\section{Head + Finite Relative Clause}

It was also observed that the postmodifiers used in the editorials of the Daily Graphic were finite relative clauses. Relative clauses are introduced by relative pronouns such as that, which, who and whom. From the data set, it was revealed that the $\mathrm{H} \mathrm{R} / \mathrm{C}$ structure occurred 33 times representing $21.1 \%$ of the occurrence in the corpus. The following examples illustrate this assertion:

14. They were not prepared to accept the situationwhere they had gone and fought and died and were being treated unfairly. [ March 1, 1988]

15. It could deprive some candidateswho by an accident of geography or profession were not resident areas. [May, 1988]

16. One areawhere government could intervene is ....[June 1, 1998]

17. They must come up with rates that seek to protect the interest of consumers [Feb 2, 1998]

18. And thosewho still doubt the credibility of the Electoral Commission. [Dec 1, 2008]

\subsection{CONCLUSION}

The study sought to investigate the diachronic changes of the NP structure in newspaper editorials. Specifically, the study sought to identify the kinds of premodifiers and postmodifiers that are used in the editorial of the Daily Graphic.Nine editorials were conveniently sampled for the study. Being a diachronic study, the research investigated editorials published in 1988, 1998 and 2008. The data revealed that the most preferred form of premodification used in editorials is the Determiner + Head $(\mathrm{DH})$. The study revealed that there has been an increase in the usage of this structure across the three years. This is followed by Determiner +Adjective + Head (DAH), Determiner + compound adjectives + Head (DAAH) and Determiner + binominals $(\mathrm{DNH})$ in that order.Concerning postmodification, it was revealed that despite some differences in their occurrence, there was an increase in the use of $\mathrm{H}$ PPs and $\mathrm{H}$ R/C structures.

The study is significant in that it adds to the knowledge in the literature and creates awareness to both journalists and readers of the Daily Graphic. The study has implications for print media discourse, Historical Linguistics and for further study.

\subsection{ACKNOWLEDGEMENT}


I am highly indebted to Dr. Joseph Arko, a lecturer at the Department of English, University of Cape Coast, for suggesting this study for me to carry out as a term paper in a Grammar course.

\section{REFERENCES}

\subsection{Primary texts}

Daily Graphic. March 1, 1988

Daily Graphic. May 2, 1988

Daily Graphic. September 1, 1988

Daily Graphic. February 2, 1998

Daily Graphic. June 1, 1998

Daily Graphic. November 1, 1998

Daily Graphic. January 1, 2008

Daily Graphic. August 1, 2008

Daily Graphic. December 1, 2008

\subsection{Works Cited}

Biber, Douglas and Edward Finnegan. (1988). Variations across Speech and writing. Cambridge University Press, Cambridge.

Biber, Douglas, Stig Johansson, Geoffrey Leech, Susan Conrad, Edward Finnegan (1999). Longman Grammar of Spoken and Written English. Pearson Educational Press, UK.

Cheung, Chi-Hang (2007). On the Noun Phrase Structure of Jingpo. USC Working Papers in Linguistics. Vol. 3 (1):32-56

Danesi, Marcel (2009). Dictionary of Media and Communications. M.E. Sharpe, Inc. USA

Dimitrova-Vulchanova, M \& Giuliana Giusti (1998), Fragments of Balkan Nominal Structure. University of Venice Working papers in Linguistics. Vol. 8 (1):141-170

Giusti, G. (1999). The functional structure of noun phrases: A bare phrase structure approach. University of Venice Working papers in Linguistics. Vol. 5 (2):105-60

Greenbaum, Sidney (1996). The oxford English Grammar. Oxford University Press, New York.

Hudson-Ettle, D. \& Tore Nilsson (1990).Orality and noun phrase structure in registers of British and Kenyan English. ICAME Journal Vol. 26 (2): 33-59

Krippendorff, K. (2004).Content analysis: An introduction to its methodology. United Kingdom Sage Publications.

Maestre, M. (1998). Noun Phrase Complexity as a Style Marker: An Exercise in Stylistic Analysis. Atlantis. Vol. 20(2):91105. Accessed on: December 11, 2013. Retrieved from:http://www.jstor.org/stable/41055516.

Mardh, I. (1980). Headlinese: On the grammar of English front page headlines. Gotab,Malmo New Times Corporation. Retrieved from http//www.newtimes.com.gh.html. Accessed on December 1, 2013.

Picard, Robert \& Jeffrey Brody (1997). The newspaper publishing industry. Alyn and Bacon.

Quirk, Randolph, Sidney Greenbaum, Geoffrey Leech, and Jan Svartvik (1985). A comprehensive grammar of the English language. London and New York: Longman.

Westin, Ingrid (2002). Language change in English Newspaper Editorials. Journal of Historical Pragmatics. Vol. 7 (1):154157

Westin, I \& Christer Geisler (2011). A multi-dimensional study of diachronic variation in British newspaper editorials. ICAME Journal Vol. 26(1): 133-150 


\section{AUTHOR'S BIOGRPAHY AND PHOTOGRAPH}

Mr. Isaac Afful holds a Bachelor of Education degree in English and is currently a Master of Philosophy student (English Language) in the Department of English at the University of Cape Coast, Ghana. His research interest areas include Academic Literacy/ Variation, Disciplinary Studies, Genre Studies, Discourse Analysis and Advanced Literacy and Writing.

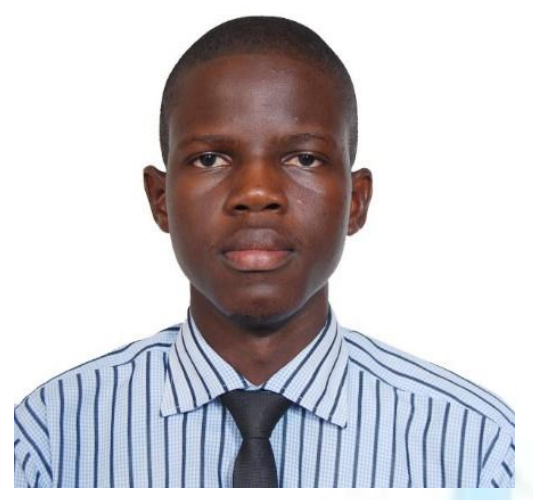

